\title{
Quality of life of Iranian $\beta$-thalassaemia major patients living on the southern coast of the Caspian Sea
}

\author{
H. Khani, ${ }^{1}$ M.R. Majdi, ${ }^{2}$ E. Azad Marzabadi, ${ }^{3}$ A. Montazeri, ${ }^{4}$ A. Ghorbani ${ }^{7}$ and M. Ramezani ${ }^{5}$
}

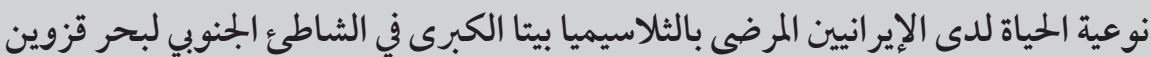

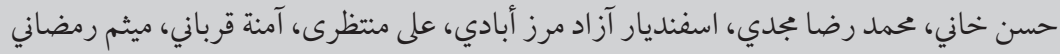

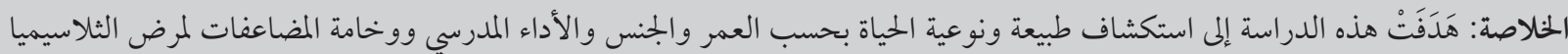

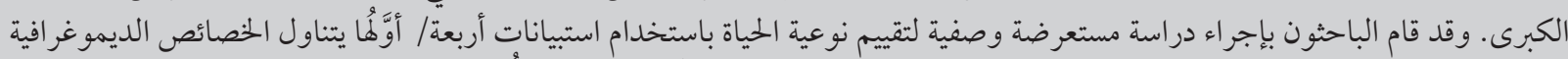

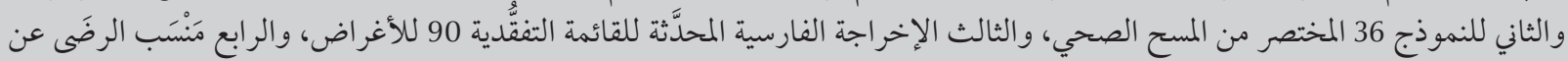

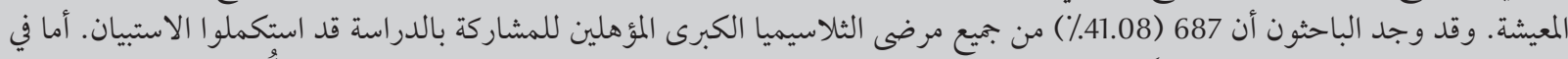

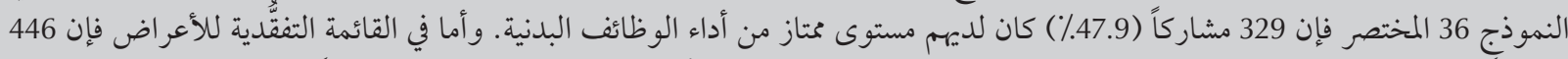

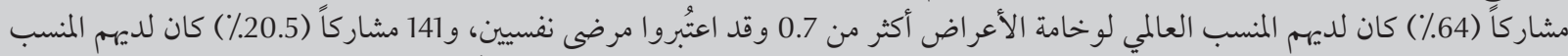

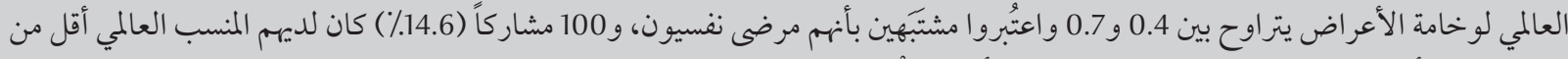

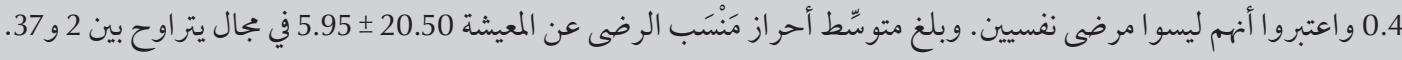

ABSTRACT In the present study, the aim was to explore the quality of life of thalassaemia major (TM) patients according to age, sex, school performance, severity and complications of the disease. A cross-sectional descriptive study was conducted. Quality of life was evaluated by 4 questionnaires; demographic characteristics, the short form 36 health survey (SF-36), Persian version of symptoms checklist-90-revised (SCL-90-R) and life satisfaction index (LSI). 687 (41.08\%) of the eligible patients with TM completed the questionnaires. With the SF-36 questionnaire, 329 (47.9\%) participants had an excellent level of physical functioning. With the SCL-90-R questionnaire, 446 (64.9\%) participants had a global severity index of $>0.7$, considered psychiatric patients, 141 (20.5\%) patients had GSI between 0.4 and 0.7 , considered suspected psychiatric patients and 100 (14.6\%) participants had GSI of $<0.4$, considered non-psychiatric patients. The mean score of LSI questionnaire was 20.50 (SD 5.95), range 2-37. BetaTM patients are at risk of psychiatric symptoms and need appropriate psychiatric counselling.

Qualité de vie de patients iraniens atteints de $\beta$-thalassémie majeure vivant sur la côte sud de la mer Caspienne

RÉSUMÉ La présente étude vise à examiner la qualité de vie de patients atteints de thalassémie majeure en fonction de l'âge, du sexe, des résultats scolaires, et de la gravité et des complications de la maladie. Une étude descriptive transversale a été menée. Dans cette étude, la qualité de vie a été évaluée au moyen de quatre outils : les caractéristiques démographiques, le questionnaire d'évaluation de la santé SF-36 en version abrégée, la version en persan de l'échelle de symptômes SCL-90-R et l'indice de satisfaction de vie. Parmi les patients éligibles souffrant de thalassémie majeure, 687 d'entre eux (41,08 \%) ont rempli les questionnaires. Selon les résultats du questionnaire SF-36, 329 participants (47,9\%) avaient un excellent niveau de capacité physique fonctionnelle. En tout, 446 participants $(64,9 \%)$ ont obtenu un indice de sévéritéglobal de plus de 0,7 (patients psychiatriques) au questionnaireSCL-90-R ; 141 participants (20,5\%) présentaient un indice de sévérité global allant de 0,4 à 0,7 (patients psychiatriques présumés); et 100 participants (14,6\%) avaient des résultats inférieurs à 0,4 (patients non psychiatriques). Le score moyen au questionnaire d'indice de satisfaction de vie était de 20,50 ( $\pm 5,95$, extrêmes $2-37$ ). Les patients souffrant de $\beta$-thalassémie majeure risquent de présenter des symptômes psychiatriques et ont donc besoin d'un accompagnement dans ce domaine.

'Iranian Applied Research Center for Public Health and Sustainable Development (IRCPHD), North Khorasan University ofMedical Sciences, Bojnurd, Islamic Republic of Iran (Corresponding author H. Khani: dr.h.khani@gmail.com). ${ }^{2}$ Mashhad University ofMedical Sciences, Mashhad, Islamic Republic of Iran. ${ }^{3}$ Behavioural Sciences Research Center, Baqiyatallah University of Medical Sciences, Tehran, Islamic Republic of Iran. ${ }^{4}$ Iranian Institute for Health Sciences Research, ACECR, Tehran, Islamic Republic of Iran. ${ }^{5}$ Iranian Institute for Young Thalassemia, Ghaemshahr, Islamic Republic of Iran. This paper was published in Farsi in the Journal of Behavioral Sciences, 2009, 2(4):325-332; the translation is published here with kind permission. 


\section{Introduction}

Beta-thalassaemia major (TM) is a chronic hereditary disease of the blood due to the defective synthesis of 1 or more globin polypeptide chains. This disease is characterized by lack of appropriate growth, overly large spleen and liver, and abnormality of the bones, particularly in the face and head, which can be observed in the physiognomy [1]. Although not curable, TM can be treated. However, these treatments are unpleasant, long and repetitive, and can affect a patient's general health, mental health and life satisfaction. These treatments can also have an impact on the families of patients, especially on siblings [2-10]. Some investigations have found that $80 \%$ of people diagnosed with TM have at least 1 psychiatric disorder [2], the most frequent being disembodiment $[3,4]$, anxiety $[5,6]$, depression [7], somatoform disorders $[8]$ and anger $[9,10]$. This disease can also have a deleterious impact on the social activities and education of patients $[11,12]$.

Some investigations have found that patients with TM are able to overcome their problems [13]. Differences, however, have been observed among countries or even among different districts of the same country [4]. The prevalence of TM in Mazandaran province of Iran has been estimated at 0.62 per thousand [14]. Many infants and teenagers in this province have TM, making it a major longterm problem for their families [15]. Due to recent advances in treatment, adolescents with TM can participate actively in social activities. Increasing public awareness of the incidence and treatment of TM can help ameliorate patient conditions and improve their quality of life.

We assessed the quality of life among Iranian beta-thalassaemia major patients aged $\geq 15$ years in Mazandaran province of the Islamic Republic of Iran.

\section{Methods}

\section{Study design}

This was a cross-sectional, populationbased study investigating the quality of life, mental health and life satisfaction among TM patients aged $\geq 15$ years and treated between 1 March and 30 November, 2008 at any of the 16 special TM units in several hospitals of Mazandaran province, Iran, located on the southern coast of the Caspian Sea.

The study protocol was approved by the ethnic review committees of 5 institutions, the Iranian Applied Research Center for Public Health and Sustainable Development (IRCPHD); North Khorasan University of Medical Sciences, Mashhad University of Medical Sciences, Behavioural Sciences Research Center; Baqiyatallah University of Medical Sciences, Iranian Institute for Health Sciences Research, Iranian Institute for Young Thalassemia and all participants gave written informed consent.

\section{Participants and procedures}

We assessed TM patients who were dependent on blood transfusions, and who visited for monthly blood transfusions and clinical examinations. TM diagnosis was based on the results of electrophoresis of blood haemoglobin. All subjects were asked to complete a 6-page self-administered questionnaire; anyone who had difficulty reading the questionnaire was provided with assistance. Of the 1672 TM patients asked to complete the questionnaire, 687 (41.08\%) did so.

\section{Measures}

The following instruments were used:

Demographic researcher-made questionnaire: In addition to information on subjects' clinical and demographic characteristics, including age, sex, marital status, educational level, educational status, disease complications, and treatment received, the questionnaire included questions on facial changes due to TM and on the deaths of near or distant relatives due to TM.

Short Form 36 Health Survey Questionnaire (SF-36): This questionnaire evaluated the general health of TM patients according to 8 categories: physical functioning, role-physical, bodily pain, general health, vitality, social functioning, role-emotional, and mental health. The Cronbach alpha the reliability of this questionnaire has been found to range from 0.77 to 0.90 in Iran and from 0.65 to 0.96 in other countries [16]. The total score of these 8 indices ranged between 0 and 100, with designations of weak $(\leq 20)$, bad $(21-40)$, good (41-60), very good (61-80), and excellent (> 81) [16].

Symptoms checklist-90-revised (SCL90-R): This scale was used to estimate the type and intensity of psychological symptoms. The questionnaire includes 9 scopes (somatization, obsessive-compulsive, interpersonal sensitivity, depression, anxiety, hostility, phobic anxiety, paranoid ideation and psychosis) and 3 indices (global severity index (GSI), with each question scored from 0 to 4; positive symptom total (PST) index, with a total score of 0 to 90; and positive symptoms distress index (PSDI), with each question scored from 0 to 4 ] to indicate the sadness, depth and degree of mental problems. In Iran, the reliability of this questionnaire has been reported to be from 0.80 for somatization to 0.90 for paranoid ideation and to range between 0.77 and 0.90 in other countries $[17,18]$. We scored participants with GSI $>0.7$ as likely to require hospitalization, those with GSI between 0.4 and 0.7 as having a probable mental illness and those with GSI $<0.4$ as probably safe and healthy. In addition, subjects with GSI scores higher than the mean score of the population were considered as likely to have mental problems, whereas those subjects with GSI lower than the mean score of the population were considered probably safe and healthy [19]. 
Life Satisfaction Index (LSI): This questionnaire consisted of 20 questions on participants' life satisfaction. Each question could be answered "agree" ( 2 points), "disagree" ( 0 points) or "I don't know" (1 point). The scores of participants ranged from 0 to 40 , with subjects categorized as unacceptable, poor, medium and acceptable [20].

\section{Statistical analysis}

Descriptive statistics were used for all items. Statistical evaluations were performed using Q-Score and $t$-test, as assessed by the Statistical Package for the Social Sciences (SPSS 17.0). A Pvalue $<0.05$ was considered statistically significant.

\section{Results}

Of the 1672 eligible patients with TM, 687 (41.08\%) completed the questionnaires. The mean age [standard deviation (SD)] of the participations was 21.93 (SD 5.90) years (range, 15-45 years). Of these individuals, 363 (52.8\%) were female and 602 (87.6\%) were unmarried. The subjects' demographic characteristics are shown in Table 1.

Of the 687 assessed TM patients, 284 (36.1\%) were diagnosed before age 6 months, 167 (24.3\%) from 6 months to 1 year, $182(26.5 \%)$ between 2 and of 5 years and $90(13.1 \%)$ after age 5 years. These patients received blood transfusions at a mean interval of 35.89 (SD 29.25) months (range, 2-144 months). Most patients $(n=620,90.24 \%)$ visited the thalassaemia health units regularly for blood transfusions. On average, each patient was transfused with 528.77 (SD 158.28) $\mathrm{mL}$ of blood at each visit. We found that 656 patients (95.8\%) were using Desferal transfusion medicine, with 650 (94.6\%) applying it subcutaneously along with the Desferal pump. Of the 687 TM patients we assessed, 437 (63.6\%) had noticeable mild to severe changes in facial bones accompanied by some changes in figures and 477 (69.4\%)

\begin{tabular}{|c|c|c|}
\hline Characteristic & No. & $\%$ \\
\hline \multicolumn{3}{|l|}{ Age (years) } \\
\hline $15-25$ & 537 & 78.2 \\
\hline $25-35$ & 127 & 18.5 \\
\hline $35-45$ & 23 & 3.3 \\
\hline Mean (SD) & $21.93(5.90)$ & \\
\hline Range & $15-45$ & \\
\hline \multicolumn{3}{|l|}{ Sex } \\
\hline Male & 324 & 47.2 \\
\hline Female & 363 & 52.8 \\
\hline \multicolumn{3}{|l|}{ Marital status } \\
\hline Single & 602 & 87.6 \\
\hline Married & 85 & 12.4 \\
\hline \multicolumn{3}{|l|}{ Education level } \\
\hline Illiterate & 28 & 4.1 \\
\hline Secondary & 123 & 17.9 \\
\hline High school & 314 & 45.7 \\
\hline Higher education & 222 & 32.3 \\
\hline \multicolumn{3}{|l|}{ Educational status } \\
\hline Normal & 435 & 63.3 \\
\hline Retarded & 252 & 36.7 \\
\hline \multicolumn{3}{|l|}{ Employment status } \\
\hline Housewife & 77 & 11.2 \\
\hline Student & 243 & 35.4 \\
\hline University student & 57 & 8.3 \\
\hline Employed & 69 & 10.0 \\
\hline Jobless & 241 & 35.1 \\
\hline
\end{tabular}

$S D=$ standard deviation .

patients showed mild to severe changes of complexion. Disease complications of thalassaemia are shown in Table 2.

The mean scores on the 8 indexes of the SF-36 Test are shown in Table 3. Physical functioning index had the highest mean score [73.58 (SD 21.89)], while vitality had the lowest mean score [52.79 (SD 12.73)]. Scores between 80 and 100 for each of the 8 indexes were achieved by 329 patients (47.9\%) for physical functioning, 224 (32.6\%) for Role-physical, 206 (30\%) for bodily pains, 83 (12.1\%) for general health, 5 (7\%) for vitality, 222 (32.3\%) for social functioning, 201 (29.3\%) for role-emotional, and 13 (1.9\%) for mental health.

Scores on the 9 scores and 3 indices of the SCL-90-R test were assessed, as shown in Table 4. GSI scores $>0.7 \%$ were observed in 449 (64.9\%) subjects, indicating a need for treatment of mental illness. In addition, 141 (20.5\%) subjects had GSI scores between $0.4 \%$ and $0.7 \%$, suggesting that they may have a mental disease. However, 100 (14.6\%) subjects had GSI scores $<0.4 \%$, indicating that they were probably safe and healthy. The mean score of GSI of 405 patients (59\%) was less than the GSI score of the population of this investigation; therefore, they were considered probably safe and healthy. In contrast, the mean score GSI score of the remaining 282 patients (42\%) was higher than the GSI score of the population, suggesting a need for mental health treatment. The mean (SD) scores of 9 scopes and 3 indexes 


\begin{tabular}{lcc}
\hline Table 2 Frequency of clinical disorders among participants $(\boldsymbol{n}=\mathbf{6 8 7})$ & \\
Characteristic & No. & $\%$ \\
Headache & 127 & 18.5 \\
Dyspnoea and chronic cough & 68 & 9.9 \\
Depression and anxiety & 158 & 23 \\
Hearing loss & 50 & 7.3 \\
Heart failure & 45 & 6.6 \\
Splenectomy & 225 & 32.8 \\
Lower back pain & 212 & 30.9 \\
Hyperthyroidism & 7 & 1 \\
Hepatitis & 92 & 13.4 \\
Visual loss & 88 & 12.8 \\
Cholecystectomy & 56 & 8.2 \\
Hypothyroidism & 15 & 2.2 \\
Hyperthyroidism & 7 & 1 \\
Osteoporosis & 63 & 9.2 \\
Bone fractures & 84 & 12.2 \\
Hypoparathyroidism & 7 & 1 \\
Allergy & 63 & 9.2 \\
Vertigo & 127 & 18.5 \\
Renal stones & 25 & 3.6 \\
Diabetes & 50 & 7.3 \\
Hypertension & 9 & 1.3 \\
Hyperlipidaemia & & 9.5 \\
\hline
\end{tabular}

of SCL-90-R test in subgroups aged $15-25$ and $25-45$ years and in males and females are shown in Table 5.

The TM patients in this study had a mean score of 20.5 (SD 5.95) (range, 2-37) on the life satisfaction questionnaire. We found that 26 participants (3.8\%) had scores corresponding to unacceptable life satisfaction, 317 (46.1\%)
[15]. TM is usually recognized in childhood, at which time patients begin treatment. Over their lives, however, patients and their families are at risk for social and behavioural disorders. Due to distress from both the illness itself and the need for iron chelation, thalassaemia subjects frequently display maladaptive coping strategies and high levels of anxiety with psychosocial dysfunction $[21,22]$. The probability of behavioural abnormality in children with TM has been estimated to be 1.6-fold higher than that in healthy children [21].

Our findings support the results of other studies [2-14] on the quality of life of TM patients and those with other chronic diseases, including Crohn disease, ulcerative colitis, cystic fibrosis, congenital heart disease, asthma, epilepsy, sweet diabetes and cancer [23--26]. These studies found that patients with these diseases show a significant decrease in life satisfaction and mental health or a significant increase in probable psychiatric disorders, including somatisation, interpersonal sensitivity, depression, anxiety and psychosis. Patients with different diseases, however, show differing intensity or type of psychiatric abnormalities. This may be due to differences in illness, the use of different research instruments, social class, ethnicity, the amount of support available to patients, previous treatments and self-coping strategies $[27,28]$.

\begin{tabular}{|c|c|c|c|}
\hline Indices of SF-36 Test & Mean (SD) score & $\begin{array}{c}\text { Group A } \\
\text { No. (\%) }\end{array}$ & $\begin{array}{c}\text { Group B } \\
\text { No. (\%) }\end{array}$ \\
\hline Physical functioning & $73.58(22.81)$ & $270(39.3)$ & $417(60.7)$ \\
\hline Role-physical & $59.06(36.90)$ & $331(48.2)$ & $356(51.8)$ \\
\hline Bodily pain & $64.45(21.03)$ & $353(51.4)$ & $334(48.6)$ \\
\hline General health & $57.88(18.15)$ & $368(53.6)$ & $319(46.4)$ \\
\hline Vitality & $52.79(12.73)$ & $349(50.8)$ & $338(49.2)$ \\
\hline Social functioning & $69.06(21.41)$ & $336(48.9)$ & $351(51.1)$ \\
\hline Role-emotional & $53.61(37.78)$ & $312(45.4)$ & $375(54.6)$ \\
\hline Mental health & 52.88 (13.94) & $360(52.4)$ & $327(47.6)$ \\
\hline
\end{tabular}

Group A: participants in this group scored lower than the mean score of the sample for each index of SF-36.

Group B: participants in this group have scored higher than the mean score of the sample for each index of SF-36.

$S D=$ standard deviation 


\begin{tabular}{|c|c|c|c|}
\hline Scopes and indices of SCL-90-R Test & $\begin{array}{l}\text { Total Patients } \\
\text { Mean (SD) scores } \\
(n=687)\end{array}$ & $\begin{array}{c}\text { Group A } \\
\text { Mean (SD) scores } \\
(n=405)\end{array}$ & $\begin{array}{c}\text { Group B } \\
\text { Mean (SD) scores } \\
(n=282)\end{array}$ \\
\hline Somatization & $0.97(0.61)$ & $0.64(0.37)$ & $1.43(0.59)$ \\
\hline Obsessive-compulsive & $0.96(0.65)$ & $0.59(0.38)$ & $1.48(0.60)$ \\
\hline Interpersonal sensitivity & $1.12(0.72)$ & $0.7(0.41)$ & $1.74(0.64)$ \\
\hline Depression & $1.13(0.76)$ & $0.66(0.38)$ & $1.8(0.67)$ \\
\hline Anxiety & $0.9(0.66)$ & $0.53(0.35)$ & $1.42(0.64)$ \\
\hline Hostility & $0.96(0.74)$ & $0.59(0.45)$ & $1.48(0.76)$ \\
\hline Phobic anxiety & $0.64(0.58)$ & $0.36(0.32)$ & $1.04(0.63)$ \\
\hline Paranoid ideation & $1.26(0.78)$ & $0.84(0.51)$ & $1.86(0.71)$ \\
\hline Psychoticism & $0.78(0.61)$ & $0.43(0.33)$ & $1.28(0.57)$ \\
\hline Global severity index & $0.97(0.02)$ & $0.6(0.25)$ & $1.51(0.44)$ \\
\hline Positive symptom total & $47.64(0.73)$ & $36.25(14.37)$ & $64(12.18)$ \\
\hline Positive symptom distress index & $1.77(0.01)$ & $1.52(0.38)$ & $2.12(0.47)$ \\
\hline
\end{tabular}

Group A: probable safe subjects having lower global severity index than the mean score of the sample in this research

Group B: probable patient subjects having higher global severity index than the mean score of the sample in this research. $S D=$ standard deviation.

Our study findings indicate that TM patients in Mazandaran province lack pre-planned instructions on life skills and lack accessibility to psychiatric consultations. These findings differ from those of a previous study [29], which found that most children become adjusted to their chronic disease and return to normal life. The marital status, level of education and educational status of TM patients were significantly lower than those of the general population, indicating that TM patients lack personality skills enabling them to adapt to their situation. The anxieties and behavioural abnormalities displayed by TM patients in previous decades were thought to be due to having to adapt to death, with adjustments associated with less depression. At present, however, due to the progress of medical remedial programmes, these patients encounter different aspects of life [30].

Moreover, inequalities between TM patients and their healthy peers, in aspects including emotional attitudes of adulthood, marriage circumstances and job opportunities, have decreased life satisfaction and increased psychiatric abnormalities in TM patients. Male and female patients have the same psychiatric abnormalities, in particular

\begin{tabular}{|c|c|c|c|c|c|c|}
\hline $\begin{array}{l}\text { Scopes and indices of SCL- } \\
\text { 90-R test }\end{array}$ & $\begin{array}{c}\text { Males }(n=324) \\
\text { Mean }(S D) \text { scores }\end{array}$ & $\begin{array}{l}\text { Females }(n=363) \\
\text { Mean }(S D) \text { scores }\end{array}$ & $P$ & $\begin{array}{l}\text { 15-25-year-olds } \\
(n=537) \\
\text { Mean (SD) scores }\end{array}$ & $\begin{array}{c}\text { 25-45-year-olds } \\
(n=150) \\
\text { Mean (SD) scores }\end{array}$ & $P$ \\
\hline Somatization & $0.96(0.6)$ & $0.98(0.62)$ & 0.688 & $0.95(0.62)$ & $1.03(0.58)$ & 0.152 \\
\hline Obsessive- Compulsive & $0.97(0.65)$ & $0.94(0.66)$ & 0.531 & $0.94(0.66)$ & $1(0.61)$ & 0.31 \\
\hline Interpersonal sensitivity & $1.13(0.72)$ & $1.12(0.72)$ & 0.924 & $1.11(0.74)$ & $1.17(0.67)$ & 0.352 \\
\hline Depression & $1.13(0.76)$ & $1.13(0.76)$ & 0.951 & $1.1(0.77)$ & $1.25(0.74)$ & 0.033 \\
\hline Anxiety & $0.88(0.64)$ & $0.91(0.67)$ & 0.456 & $0.87(0.65)$ & $0.98(0.67)$ & 0.094 \\
\hline Hostility & $0.98(0.76)$ & $0.94(0.73)$ & 0.486 & $0.93(0.73)$ & $1.04(0.78)$ & 0.126 \\
\hline Phobic anxiety & $0.64(0.56)$ & $0.64(0.59)$ & 0.928 & $0.62(0.56)$ & $0.71(0.62)$ & 0.083 \\
\hline Paranoid ideation & $1.22(0.75)$ & $1.3(0.80)$ & 0.193 & $1.24(0.79)$ & $1.34(0.73)$ & 0.142 \\
\hline Psychoticism & $0.79(0.62)$ & $0.78(0.60)$ & 0.804 & $0.77(0.62)$ & $0.82(0.58)$ & 0.360 \\
\hline Global severity index & $0.97(0.55)$ & $0.98(0.62)$ & 0.688 & $0.95(0.62)$ & $1.03(0.58)$ & 0.152 \\
\hline Positive symptom total & $47.83(18.43)$ & $0.94(0.66)$ & 0.531 & $0.94(0.66)$ & $1(0.61)$ & 0.31 \\
\hline $\begin{array}{l}\text { Positive symptom distress } \\
\text { index }\end{array}$ & $1.75(0.51)$ & $1.12(0.72)$ & 0.924 & $1.11(0.74)$ & $1.17(0.67)$ & 0.352 \\
\hline
\end{tabular}

$P<0.05$ was considered to be statistically significant.

$S D=$ standard deviation. 
anxiety and behavioural abnormalities until adulthood; afterwards these abnormalities intensify more in females than in males [31]. Some studies have not found any gender-related differences in the prevalence of behavioural abnormalities in children with chronic diseases [28]. In some diseases such as asthma and epilepsy, girls show higher rates of depression than boys [32], whereas in other diseases such as cancer, depression is seen more in boys [33]. We found, however, that the frequency of mental difficulties, as assessed by a GSI $\geq 0.7 \%$ mean score, was heightened in both genders, albeit equally. The latter may be due to the delay in sexual maturation in TM patients [34].
The intensity of mental abnormalities in both genders and the similarity of mental and social anxiety factors in boys and girls suggest the necessity for these patients to have access to psychiatric consultants. The lack of significant differences among age groups suggests that these patients have the same emotional and social needs, regardless of age [7].

The major limitation of this study was the relatively low participation rate, in that only $41 \%$ of the eligible patients participated. The uneven participation of the subjects may have been due to the severe mental and emotional disorders of TM patients at the time the survey was administered.

We found that TM patients seen in special TM units in hospitals of
Mazandaran province, on the southern coast of the Caspian Sea in Iran, are on the verge of suffering from different sorts of psychiatric abnormalities, indicating a need to consult with proficient psychiatric consultants to be taught life skills and how to deal with the social and emotional disorders accompanying TM for improvement of their quality of life.

\section{Acknowledgements}

The authors thank the study sites and instructors for their valuable contribution. The authors are thankful for contributions of those who helped to carry this study especially the researchers who evaluated the questionnaires and those who carried out the interviews.

\section{References}

1. Kasper DL et al. Harrison's principles of internal medicine,16th ed. New York, McGraw-Hill, 2005

2. Aydin B et al. Psychosocial aspects and psychiatric disorders in children with thalassemia major. Acta Pediatrica Japanonica, 1997, 39:354-357.

3. Hoch C, Gobel U, Janssen G. Psychosocial support of patients with homozygous beta-thalassemia. Clinical Pediatrics, 2000 212(4):216-219.

4. Tsiantis J et al. Psychosocial problems and adjustment of children with beta-thalassemia and their families. European Child \& Adolescent Psychiatry, 1996, 5(4):193-203.

5. Z. Pourmovahed Kh. Dehghani M, Ardakani Y. [Evaluation of hopelessness and anxiety in young patients with thalassemia major]. Journal of Medical Research (JMR), 2003, 2(1):45-52. [In Farsi].

6. Ghaffari Saravi V, Zarghami M, Ebrahimi E. [The prevalence of depression in Thalassemic patients in the city of Sari]. Iranian Journal of Psychiatry and Clinical Psychology (Andeesheh Va Raftar), 2004, 9(35):40-33 [In Persian].

7. Khodaei Sh, Karbakhsh M, Asasi N. [Psychosocial status in Iranian adolescents with beta-thalassemia major]. Journal of the Tehran Faculty of Medicine, 2005, 63(1):23-18 [In Farsi].

8. Monastero $\mathrm{R}$ et al. Cognitive deficits in beta-thalassemia major. Acta Neurologica Scandinavica, 2000, 102(3):162-168

9. Noll RB et al. Social, emotional and behavioral functioning of children with cancer. Pediatrics, 1999, 103(1):71-78.

10. Lavigne JV, Ryan M. Psychological adjustment of siblings of children with chronic illnesses. Pediatrics, 1979, 63(4):616627.

11. Di Palma A et al. Psychosocial integration of adolescents and young adults with thalassemia major. Annals of the New York Academy of Sciences, 1998, 850:355-360.

12. Bush S, Mandel FS, Giardina PJ. Future orientation and life expectations of adolescents and young adults with thalassemia major. Annals of the New York Academy of Sciences, 1998, 850:361-369.
13. Goldbeck L, Baving A, Kohne E. Psychosocial aspects of betathalassemia: distress, coping and adherence. Clinical Pediatrics, 2000, 212(5):254-259.

14. Gharakhail A, Abedian M. Prevalence of beta thalassemia major in Mazandaran Province, Iran [Thesis]. Mazandaran, School of Medicine, Mazandaran University of Medical Sciences, 1997.

15. Olivieri NF. The beta-thalassemias. New England Journal of Medicine, 1999, 341:99-109.

16. Montazeri A et al. The Short Form Health Survey (SF-36): Translation and validation study of the Iranian version. Quality of Life Research, 2005, 14(3):875-882.

17. Derogatis LR, Rickels K, Rock A. The SCL-90 and the MMPI: a step in the validation of a new self-report scale. British Journal of Psychiatry, 1976, 128:280-289.

18. Mirzai R. Standardizing and validating of SCL-90-R in Iran. Archives of Iranian Medicine, 2009, 1(12):5-14.

19. Bagheri Yazdi A, Bolhari J, Shah Mohammadi D. [An epidemiological study of psychological disorders in a rural area (Meibod, Yazd)]. Iranian Journal of Psychiatry and Clinical Psychology (Andeesheh Va Raftar), 1994, 1(1):41-32 [In Farsi].

20. Neugarten BL, Butler N, Dawson I. Engagement levels on a unit for people with a physical disability. Clinical Rehabilitation, 1989, (3):299-304.

21. Jarman F, Oberklaid F. Children with chronic illness: Factors affecting psychosocial adjustment. Current Opinion in Pediatrics, 1990, 2(3):868-872.

22. Gortmaker SL et al. Chronic conditions, socioeconomic risk and behavior problems in children and adolescents. Journal of Pediatrics, 1990, 85(3):267-276.

23. Holden EW, Chmieiewski D, Nelson CC. Controlling for general and disease-specific effects in child and family adjustment to chronic childhood illness. Journal of Pediatric Psychology, 1997, 22:15-27.

24. Drotar D, Crawford P. Psychological adaptation of siblings of chronically ill children: Research and practice implica- 
tion. Journal of Developmental and Behavioral Pediatrics, 1985, 6:355-362

25. Canning EH, Canning RD, Boyce WE. Depressive symptom and adaptive style in children with cancer. Journal of the American Academy of Child and Adolescent Psychiatry, 1992, 31:1120-1124.

26. Kovacs M et al. Psychological functioning of children with insulin dependent diabetes mellitus: a longitudinal study. Journal of Pediatric Psychology, 1990, 15(5):619-632.

27. Burke $P$ et al. Depression and anxiety in pediatric inflammatory bowel disease and cystic fibrosis. Journal of the American Academy of Child and Adolescent Psychiatry, 1989, 28:948-951.

28. Youssef NM. Scholl adjustment of children with congenital heart disease. Maternal-Child Nursing Journal, 1988, 17:217-302.

29. Eiser C. Psychological effects of chronic disease. Journal of Child Psychology and Psychiatry, and allied disciplines, 1990, 31:85-98.
30. Kaplan H, Sadock B. Synopsis of psychiatry, 9th ed. Baltimore, Williams \& Wilkins, 2003.

31. Kashani J et al. Psychology in a community sample of children and adolescent: a development perspective. Journal of the American Academy of Child and Adolescent Psychiatry, 1989, 28:701-706.

32. Austin JK. Comparison of child adaptation to epilepsy and asthma. Journal of the American Academy of Child and Adolescent Psychiatry, 1989, 2:139-144.

33. Kashani J, Hakami N. Depression in children and adolescents with malignancy. Canadian Journal of Psychiatry, 1982, 27(6):474-477.

34. Melevendi C. Growth and sexual maturation in thalassemia major. Journal of Pediatrics, 1985, 106:150-155.

\section{Community genetics services. Report of a WHO Consultation on community genetics in low-and middle-} income countries, Geneva, Switzerland, 13-14 September 2010

The objective of the above-mentioned Consultation was to develop an evidence-based report on community genetics services to provide guidance to low- and middle-income countries (LMIC) in accordance with the 2008-2013 Action Plan for the Global Strategy for the Prevention and Control of Noncommunicable Diseases. The goal of community genetics in LMIC is to prevent congenital disorders and genetic diseases at the population level and, at the same time, to provide genetics services (diagnosis and counselling) in the community for individuals and families.

The Consultation included a group of internationally-recognized specialists in the field of community genetics in LMIC. The group agreed that availability of community genetics services in LMIC is less than adequate. The report presents the deliberations of the group and its recommendations.

Further information about this and other WHO publications is available at: http://www.who.int/publications/en/ 